\title{
Pandemi Sürecinde Uzaktan Eğitim Ortamlarının Kullanımına İlişkin Tutum Ölçeği
}

DOI: 10.26466/opus.811510

\author{
Ezgi Pelin Yildiz $^{*}$ - Metin Çengel ${ }^{* *}$ - Ayşe Alkan ${ }^{* * *}$ \\ * Dr. Öğr. Üyesi, Kafkas Üniversitesi/Kazım Karabekir Teknik Bilimler Meslek Yüksek Okulu Bilgisayar \\ Programcılığı Bölümü, Kars, TÜRKIYE \\ E-Posta: yildizezgipelin@gmail.com \\ ORCID: 0000-0002-9987-9857 \\ **Dr. Öğr. Üyesi, Sakarya Üniversitesi/Hendek Teknik Bilimler Meslek Yüksek Okulu Bilgisayar \\ Programcılığı Bölümü, Sakarya,Türkiye \\ E-Posta: \\ akarya.edu.tr \\ ORCID: 0000-0003-0054-3120 \\ ***Dr., Samsun İl Milli Eğitim Müdürlüğü, Samsun, Türkiye \\ E-Posta: ayshe alkan@hotmail.com \\ ORCID: $\underline{0000-0002-9125-1408}$
}

\begin{abstract}
Öz
Dünyada birçok ülkeyi etkileyen Covid-19 pandemisinden ülkemizin de etkilenmesiyle bir süre önce yüz yüze eğitime ara verilip uzakta eğitim sistemine geçilmiştir. Bu bağlamda farklı seviyelerde uygulanan uzaktan eğitim, çoğu eğitim paydaşı için yabancıyken birden hayatımızın içine girmiştir. Pandemi ile birlikte gelen sosyal izolasyon döneminde öğrenenlerin uzaktan eğitime olan talebi artmıştır. Bu araştırmada, öğrenenlerin Pandemi Sürecinde Uzaktan Ĕ̆itim Ortamlarının Kullanımına İlişkin Tutumlar üzerinde durulmuş ve bu bağlamda geçerli ve güvenilir bir ölçek ortaya koyma amaçlanmıştır. Tüm bunlar ışığında bu araştırmayla ortaya konulan geçerliği ve güvenirliği kanıtlanmış ilgili ölçeğin, farklı kademelerdeki öğrenci çalışma grupları üzerinde etkili bir şekilde kullanılacağı öngörülmektedir. Ölçeğin geçerlik ve güvenirlik çalışmaları, Sakarya Üniversitesi 'nin çeşitli Fakülte ve Sakarya Uygulamalı Bilimler Üniversitesi Hendek MYO'nun farklı bölümlerde öğrenim gören toplam 321 öğrenci ile gerçekleştirilmiştir. Ölçeğin kapsam ve görünüş geçerliği için 1 dil uzmanına, 3 alan uzmanına, 1 psikolojik danışmana, 1 ölçme değerlendirme uzmanına başvurulmuştur. Yapı geçerliğine hizmet etmek için Açımlayıcı Faktör Analizi (AFA)'dan yararlanılmıştır. Çalışma sonunda toplam varyansın \%73.42'sini açıklayan 24 maddeden oluşan 4 boyutlu bir ölçek elde edilmiştir. Ölçeğin Cronbach Alpha ile hesaplanan iç tutarlık katsayısı .93' dür. Doğrulayıcı faktör analizine ilişkin 4 boyut bağlamında nihai uyum indekslerinin istenilen sınırlarda olduğu tespit edilmiştir.
\end{abstract}

Anahtar Kelimeler: Pandemi, Uzaktan Ĕ̆itim, Ortam, Tutum, Ölçek Geliştirme. 


\title{
Attitude Scale Regarding the Use of Distance Education Environments in the Pandemic Process
}

\begin{abstract}
As our country was affected by the Covid-19 pandemic, which affects many countries around the world, face-to-face education was interrupted a while ago and distant education system was introduced. In this context, distance education, which is applied at different levels, has suddenly entered our lives while being foreign to most education stakeholders. During the social isolation period that came with the pandemic, the demand of learners for distance education increased. In this study, learners' Attitudes towards the Use of Distance Education Environments in the Pandemic Process were emphasized and in this context, it was aimed to present a valid and reliable scale. In the light of all these, it is predicted that the relevant scale, whose validity and reliability has been proven, will be used effectively on study groups of students at different levels. Validity and reliability studies of the scale were carried out with a total of 321 students studying at various faculties of Sakarya University and different departments of Sakarya University of Applied Sciences Hendek Vocational School. For the content and appearance validity of the scale, 1 linguist, 3 field experts, 1 psychological counselor and 1 assessment and evaluation specialist were consulted. Exploratory Factor Analysis (EFA) was used to serve the construct validity. At the end of the study, a 4-dimensional scale consisting of 24 items that explains $73.42 \%$ of the total variance was obtained. The internal consistency coefficient of the scale calculated with Cronbach Alpha is .93. It was determined that the CFA fit indices in the context of 4 dimensions regarding the confirmatory factor analysis were within the desired limits.
\end{abstract}

Keywords: Pandemic, Distance Education, Environment, Attitude, Scale Development. 


\section{Giriş}

Pandemi ile birlikte gelen sosyal izolasyon döneminde öğrenenlerin uzaktan eğitime olan talebi artmıştır. Uzaktan eğitimin zamandan ve mekândan esneklik sağlama, öğrenenlerin kendi hızlarında öğrenmesi gibi birçok avantajının yanı sıra psikolojik ve pedagojik açıdan üniversite düzeyinde gerçekleştirilen eğitim etkinliklerinin her kademeye uygulanması sırasında yaşanabilecek çeşitli sorunlardan da bahsetmek mümkündür (Moore, Deane ve Galyen, 2011). Bu bağlamda ilkokulda öğrenim gören bir öğrenciye lise öğrencisine ders anlatır gibi ders anlatmak doğru bir yaklaşım olmayacaktır; bu noktada ders sürelerinin kademelere göre ayarlanması uzmanlar tarafından tavsiye edilmektedir. Bir diğer sınırlılık ise; yüz yüze ders anlatmaya alışmış bir öğretmenin kamera karşısında ders anlatma konusunda hiçbir deneyimi olmamasıdır. Bu durumun uzaktan eğitim ortam ve araçlarının kullanımında, kaygı düzeylerini arttırdığı öngörülmektedir.

Pandemi dönemi içerisinde uzaktan eğitime yönelik eş zamanlı (senkron) sınıf araçlarının ve özellikle Öğrenme Yönetim Sistemlerinin kullanımı ön plana çıkmıştır. Bu bağlamda Öğrenme Yönetim Sistemleri (ÖYS), uzaktan eğitim faaliyetlerini gerçekleştirmek üzere kullanılan web yazılımlarıdır (Turnbull, Chug ve Luck, 2019).

ÖYS sinıfina giren birçok araç bulunmakla birlikte, açk kaynak kodlu oluşu, kullanım kolaylığı, tek bir kullanıcı ara yüzüne sahip olma, video konferans desteği gibi avantajlarıyla Moodle ÖYS dikkat çekmektedir (Güven \& Güven, 2016; Arribillaga ve Bezanilla, 2020; Rodrigues, 2020). Moodle aynı zamanda, çevrimiçi öğrenmede gereksinim duyulabilecek ihtiyaçların büyük bir kısmına cevap verebilecek, çevrimiçi ders ve kurs yönetim sistemleri olarak tüm kullanıcılar (öğrenci, yönetici, öğretim elamanı) tarafından kolaylıklar kullanılabilecek platformlardandır (Kaleci ve Kapıdere, 2014). Moodle ayrıca 235 ülkede kullanılmakla birlikte 82 dilde desteği mevcuttur. Bunun yanı sira 50.000 öğrencili ve binlerce kurslu örnekleri de mevcuttur.

Moodle modüllerine bakıldığında, ödev, sınav, forum, tartışma panoları, haber bültenleri gibi hemen hemen tüm ağ öğrenme platformlarına sahip bir işlevselliği de içerisinde barındırmaktadır. Özetle, prestijli birçok açık kaynak ders yönetim sistemi olan Moodle bugün okullarda, eğitim kurumlarında hatta ticari kurumlarda verilen eğitimlerde yaygın olarak kullanıcılar tarafından tercih edilmektedir (Tuluk ve Seferoğlu, 2016). Alan yazın incelendiğinde 
Younus (2019) araştırmasında eğitimde ÖYS kullanımı açık kaynak öğrenme yönetim sistemlerinin karşılaştırılmasına yönelik bir çalışma yapmış; sonuç olarak araştırmaya dahil edilen Moodle, OpendX ve Sakai ÖYS'lerin içerisinde Moodle'ın diğer platformlara göre akademik ihtiyaçların karşılanması açısından en iyi özelliklere sahip olduğu ortaya konulmuştur. Yıldız, Tezer \& Uzunboylu (2018), araştırmasında Çevrimiçi Öğrenme Ortamında Moodle LMS ile İlgili Öğrenci Görüşü Ölçeği'ni geliştirmiş ve genel anlamda bir Eğitim Çevrimiçi Öğrenme Ortamında Moodle LMS ile ilgili öğrenci görüşlerinin pozitif olduğu ortaya konulmuştur.

Diğer bir popüler ÖYS Blackboard sistemi ise, en basit ifadeyle örgün öğretim süreçlerini dijital ortama taşıyan bir ÖYS'dir. Blackboard, günümüzdeki teknolojik gelişmelerin eğitime yansıması sonucu oluşan Eğitim Teknolojileri kavramının ortaya çıkardığı bir sistemdir. Merkezi ABD'de de bulunan Blackboard, üniversite ve K12 seviyesinde dünyanın önde gelen ÖYS'lerinden biridir (Bradford, Porciello, Balkon ve Backus, 2007).

Blackboard ülkemizde de çeşitli kurumlar tarafından her geçen gün artarak kullanılan bir ÖYS'dir. Özellikle Covid-19 Pandemisi süresince uzaktan eğitim faaliyetlerinin en sorunsuz şekliyle yürütüldüğü sistemlerin başında gelmektedir. Bu sistem aracıllğı ile öğretmenler, ders materyallerini (dosya, video vb.) öğrencileriyle paylaşabilir, duyuru, mesaj ve e-posta gibi iletişim araçlarını kullanabilir, test-ödev gibi değerlendirme araçlarından yararlanabilir, tartışma forumlarını kullanarak sınıf içi etkileşimi dijital ortamlarda gerçekleştirebilir (Hamilton, vd., 2014). Ayrıca sanal sınıf ortamlarında eşzamanlı olarak canlı ders oturumların gerçekleştirebilirler. Bu ortamlarda gerçekleştirilen dersler kaydedildiği için istenildiği zaman tekrar tekrar izlenebilir. Böylece her öğrencinin kendi hızlarında öğrenmelerine destek verilebilir. Araştırmanın bir diğer değişkeni tutumdan bahsedilecek olursa, tutum bir sorunu ele alış biçimi, sorun karşısında kişinin aldığı durum ve gösterdiği davranıştır (Mıdık, 2018). Bu bağlamda hem eğitimcilerin hem de öğrencilerin teknolojiye karşı sergilemiş oldukları tutumlar ön plana çıkmaktadır. Teknolojinin eğitime entegrasyonun başarılı olması ancak teknolojiye karşı olumlu tutum geliştiren ve kaygı düzeyi en az olan eğitimci, yönetici ve öğretmenlerle mümkündür (Weil ve Rosen, 1990). Öğrencilerin bilgisayar alanında çalışmaları büyük ölçüde dijital teknolojiye yönelik tutumlarına bağlldır (Cabı, 2016). Öğrenenlerin Uzaktan Eğitim ortamlarında yürütülen ders- 
lere yönelik tutumları incelendiğinde; Bayram vd., (2019)'un yaptıkları çalışmanın sonuçlarına göre kız öğrencilerin erkek öğrencilere oranla uzaktan eğitim derslerinin daha fazla avantaja sahip olduklarını düşündükleri sonucu ortaya konulmuştur.

Konuya yönelik alan yazın incelendiğinde; Durak vd., (2020) araştırmalarında Covid-19 pandemisi döneminde Türkiye'deki üniversitelerin uzaktan eğitime geçişte yaptıkları çalışmaları incelemişlerdir. Sonuç olarak en çok kullanılan öğrenme yönetim sisteminin Moodle ve ALMS olduğu; en çok kullanılan ders yazılımlarının ise Big Blue Button ve Perculus olduğu tespit edilmiş̧ir. Ayrıca Yükseköğretim Kurulunun senkron eğitim tavsiyelerine rağmen tüm derslerini senkron olarak yürütebilen üniversite sayısının sadece altı olduğu saptanmıştır. Serçemeli ve Kurnaz (2020), araştırmalarında üniversite öğrencilerinin uzaktan eğitime yönelik bakış açılarını incelemişler sonuç olarak öğrencilerin uzaktan eğitim sistemini çok fazla benimsemedikleri buna rağmen sistemin kullanımıyla ilgili öz yeterlik açısından herhangi bir problem yaşamadıkları görülmüştür. Bir diğer çalışma Dhawan (2020), çevrimiçi öğrenmeye yönelik SWOOC analizi yapmışlar; sonuç olarak zaman ve yer esnekliği, hızlı geri dönüş güçlü yönler -teknik zorluklar, teknik zorluklar, öğrenenlerin kabiliyetleri \& uyum seviyeleri ve zaman yönetimi zayıf yönlerinovasyon dijital geliştirme kapsamı, esnek program tasarımları, problem çözme/eleştirel düşünme ve uyarlanabilirlik becerileri firsatlar ve BİT altyapısının eşitsiz dağılımı, eğitim kalitesi ve dijital okuryazarlık becerileri engeller kategorisinde tanımlamışlardır.

Sonuç olarak; pandemi sürecinde değişime uğrayan öğrenme ortamlar1nın etkililiği ve başarısını destekleyen faktörler arasında öğrenci tutumlarının olduğu da göz önünde bulundurulduğunda, öğrencilerin uzaktan eğitim ortamlarını değerlendirip bu ortamlara karşı olan tutumlarını ortaya koyabilecek bir ölçeğin geliştirilmesinin literatüre katkı sağlayacağı öngörülmektedir.

\section{Araştırmanın Amacı}

Bu araştırmada, öğrenenlerin Pandemi Sürecinde Uzaktan Eğitim Ortamlarının Kullanımına İlişkin Tutumları üzerinde durulmuş ve bu bağlamda geçerli ve güvenilir bir ölçek ortaya koyma amaçlanmıştır. 


\section{Araştırmanın Önemi}

Dünyada birçok ülkeyi etkileyen Covid-19 pandemisinden ülkemizin de etkilenmesiyle bir süre önce yüz yüze eğitime ara verip uzaktan eğitime geçildi. Bu bağlamda eğitimin tüm paydaşları (öğretmen, öğrenci, öğretim elemanı, yönetici gibi) aynı anda birçok yeni duruma uyum sağlama çabasının dışında birçok dijital aracı etkin bir şekilde kullanabilme yetkinliğine de sahip olmak zorunda kalmıştır. Bu süreç içerisinde kullanıcıların bu tür dijital araçları kullanmaya yönelik yetkinlikleri ve tutumları (memnuniyet, motivasyon, etkililik gibi) şüphesiz ki önem taşımaktadır. Bu bağlamda bu araştırmayla ortaya konulan geçerliği ve güvenirliği kanıtlanmış ilgili ölçeğin, hem öğretmen/öğretim elamanı hem de farklı kademelerdeki öğrenci çalışma grupları üzerinde etkili bir şekilde kullanılacağı öngörülmektedir. Bunun yanı sıra ilgili ölçekle, paydaşların Covid-19 Pandemi süreci boyunca uzaktan eğitim araçlarını kullanım konusunda yaşadıkları sistemsel, donanımsal ve/veya psikolojik sorunlar ortaya konulacak ve bu bağlamda çözüm önerileri sunulacaktir.

\section{Yöntem}

Araştırmanın yöntem kısmında izlenen adımlar aşağıda verilmiştir:

\section{Çalışma Grubu}

Araştırmanın çalışma grubunu 2019-2020 yılı Bahar Dönemi Sakarya Üniversitenin farklı fakültelerinde ve Sakarya Uygulamalı Bilimler Üniversitesi Hendek MYO'nun farklı bölümlerde öğrenim gören toplam 321 öğrenci oluşturmaktadır. Çalışma grubuna ait demografik veriler aşağıda sunulmuştur:

- Çalışma grubunun \% 58.6'sinı ( $\mathrm{f}=188$ ) erkek öğrenciler oluşturmaktadır. Çalışma grubunun yaş sıklığını \% 53.0'ını ( $\mathrm{f}=170$ ) 17-24 yaş grubu oluşturmaktadır.

- Çalışma grubunun öğrenim gördüğü okullar: \%70.1 (f=225) Fakülte ve \%29.9 ( $\mathrm{f}=96$ ) Meslek Yüksek Okulu'dur. Çalışma grubunun bölümleri: \%42.1 (f=135) İşletme, \%15 (f=48) Bilgisayar Programcllı̆̆ı, \%14.3 (f=46) Endüstri Mühendisliği, \%11.8 (f=38) İnşaat Teknolojisi, \%9.3 (f=30) Spor Yüksek Okulu, \%5.6 ( $\mathrm{f}=18$ ) Kimya, \%1.9 (f=6) Halkla İlişkiler Bölümüdür.

- Çalışma grubunun sinıfları: \%44.2 (f=142) 1. Sınıf, \%25.9 (f=83) 2. Sinıf, $\% 21.5(\mathrm{f}=69)$ 4. Sinif ve \%8.4 (f=27) dir. 
- Çalışma grubunu oluşturan öğrenciler "bilgisayarınız var mı" sorusuna sıklıkla \%77.9 (f=250) "evet" yanıtını vermişlerdir. "İnternet bağlantı türünüz" sorusuna sıklıkla \%70.4 (f=256) "kablosuz bağlantı" yanıtı verilmiştir. "Kaç saat bilgisayar kullanıyorsunuz" sorusuna sıklıla \%48.9 ( $\mathrm{f}=150)$ "3-4 saat arası" yanıtı verilmiştir.

- Çalışma grubunu oluşturan öğrenciler "uzaktan eğitim tecrübeniz var mı" sorusuna sıklıkla \%57.0 ( $\mathrm{f}=183$ ) "hayır" cevabını vermişlerdir ayrıca aldıkları uzaktan eğitim türünün sıklıkla \%63.9 (f=205) "senkron eğitim" olduğunu belirtmişlerdir.

- Çalışma grubunu oluşturan öğrenciler "kullandıkları uzaktan eğitim ortamını" sıklıkla \%73.8 (f=237) "diğer" olduğunu belirtmişlerdir. Son olarak "uzaktan eğitime başlamadan önce eğitim aldınız mı" sorusuna ise sıklıkla \%83.5 (f=268) "hayır" cevabını vermişlerdir.

\section{Veri Toplama Araci}

Pandemi Sürecinde Uzaktan Eğitim Ortamlarının Kullanımına İlişkin Tutum Ölçeği: İlgili ölçeğin geliştirilmesine yönelik öncelikle kapsamlı bir literatür taraması yapılmıştır. Öncelikle geliştirilen ölçek için kuramsal temele dayalı 25 maddelik bir havuz oluşturulmuştur. Buna ilaveten madde havuzuna öğrencilerin demografik özelliklerini ortaya koyan 10 madde eklenmiştir.

Ölçeğin Tanıtılması : Elde edilen veriler doğrultusunda yapılan analiz çalışmaları ölçeğin 24 maddeden oluşan 4 faktörlü bir yapısının doğruluğunu göstermektedir. Ölçek 5'li Likert tipi (Kesinlikle Katılıyorum=5, Katılıyorum=4, Kararsızım=3, Katılmıorum=2, Kesinlikle Katılmıyorum=1) yapıya sahiptir. Ölçek 4 boyuttan oluşmaktadır. Birinci boyut: "yeterlilik ve motivasyon" olup 7 maddeden oluşmaktadır. İkinci boyut: "kullanılabilirlik" olup 8 maddeden oluşmaktadır. Üçüncü boyut: "etkililik" olup 5 maddeden oluşmaktadır. Dördüncü boyut: "memnuniyet” olup 4 maddeden oluşmaktadır.

\section{Bulgular}

\section{Ölçeğin Geçerlik Çalışması}

Ölçek maddelerinin çalışma grubu üzerindeki dağılımını göstermek için Açımlayıcı Faktör Analizi (AFA) yapılmıştır. Açımlayıcı faktör analizi (AFA) 
sonuçlarına göre öz değeri 1'den büyük dört faktörlü yapısını bozduğu düşüncesiyle ölçek madde sayısı 25'ten $24^{\prime}$ e indirilmiştir. Ölçeğin öz değeri 1 'den büyük 24 maddeden oluşan dört faktörlü yapısı toplam varyansın \%73.42'sini açıklamaktadır. Bu açıklanan varyans oranının \%30'un üzerinde olması, davranış bilimlerinde yapılan test geliştirme çalı̧̧malarında yeterli görülmektedir (Rennie 1997; Büyüköztürk, 2018). Yapılan geçerlik ve güvenirlik çalışmalardan sonra elde edilen sonuçlar ölçeğin kendi içerisinde tutarlı bir yapısının olduğunu kanitlamaktadır.

\section{Açımlayııı Faktör Analizi}

Ölçekten elde edilen veriler normal dağıldığından faktör analizi işleminde "Principal Component Analysis" metodu kullanılmıştır. Bunlardan en yaygin kullanılanı Temel Bileşenler (Principal Components) metodudur (Hutcheson \& Sofroniou, 1999).

Açımlayıcı faktör analizinin yapılabilmesi için öncelikle "Pandemi Sürecinde Uzaktan Eğitim Ortamlarının Kullanımına İlişkin Tutum Ölçeği" ölçeğinin yeterliliğini test eden Kaiser-Meyer-Olkin (KMO) testine bakılmıştır. KMO değeri 93 olarak bulunmuştur. Field (2000)'e göre KMO sınır değerinin .80 'den büyük oluşu "mükemmel uyuma" işaret etmektedir. Ayrıca Barlett küresellik testi sonuçları incelendiğinde ki-kare $\left(X^{2}(321)=3022.014 ; \mathrm{p}<.01\right)$ değerinin anlamlı olduğunu göstermektedir.

Maddelerin faktörlerdeki durumunu göstermek için döndürme işlemi yapılmıştır. AFA' den elde edilen sonuçlar ölçeğin dört boyutlu bir yapısının olduğunu doğrulamıştır. Bu boyutlar, "Yeterlilik ve Motivasyon" (YM), Kullanılabilirlik (K), Etkililik (E) ve Memnuniyet (M) olup Şekil 1' de görülmektedir. Ayrıca maddelerin bulunduğu faktörlerdeki yük değerleri ile ortak faktör varyansı Tablo 1'de ortaya konulmuştur. 


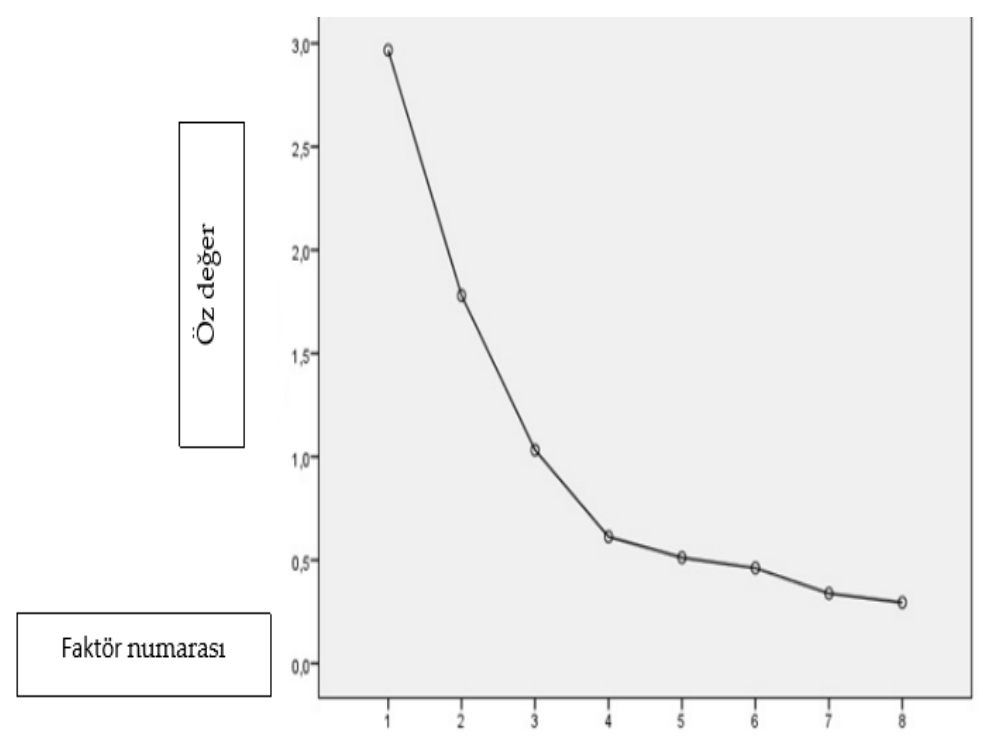

Şekil 1. Pandemi Sürecinde Uzaktan Eğitim Ortamlannın Kullanımına İlişkin Tutum Ölçeği Ölçeğinin Öz değer-faktör sayısı grafiği

Tablo 1. Açımlayıcı Faktör Analizi Sonuçlan

\begin{tabular}{|c|c|c|c|c|c|c|c|c|c|}
\hline & \multicolumn{3}{|c|}{ Başlangıç Özdeğerleri } & \multicolumn{3}{|c|}{$\begin{array}{l}\text { Yükler Karesinin Çıkarımı } \\
\text { Toplamı }\end{array}$} & \multicolumn{3}{|c|}{$\begin{array}{l}\text { Yükler Karesinin } \\
\text { Döndürme Toplamı }\end{array}$} \\
\hline & Toplam & $\begin{array}{l}\text { Varyans } \\
\%\end{array}$ & $\begin{array}{l}\text { Birikimli } \\
\%\end{array}$ & Toplam & $\begin{array}{l}\text { Varyans } \\
\%\end{array}$ & $\begin{array}{l}\text { Birikimli } \\
\%\end{array}$ & Toplam & $\begin{array}{l}\text { Varyans } \\
\%\end{array}$ & $\begin{array}{l}\text { Birikimli } \\
\%\end{array}$ \\
\hline 1 & 13.365 & 53.462 & 53.462 & 13.365 & 53.462 & 53.462 & 5.546 & 22.182 & 22.182 \\
\hline 2 & 2.431 & 9.725 & 63.187 & 2.431 & 9.725 & 63.187 & 4.539 & 18.157 & 40.339 \\
\hline 3 & 1.403 & 5.610 & 68.798 & 1.403 & 5.610 & 68.798 & 4.293 & 17.174 & 57.512 \\
\hline 4 & 1.181 & 4.722 & 73.520 & 1.181 & 4.722 & 73.520 & 4.002 & 16.007 & 73.520 \\
\hline
\end{tabular}

\section{Güvenirlik}

Çalışmanın güvenirliğini test etmek amacıyla ölçeğin 24 maddeden oluşan 4 faktörlü yapısının Cronbach Alpha ile saptanan iç tutarlık katsayısı .93 olarak saptanmıştır. Ölçeğin alt boyutlarına yönelik yapılan istatistiksel analizler sonunda Cronbach Alpha ile hesaplanan iç tutarlık katsayıları yeterlik ve motivasyon boyutuna yönelik .94; kullanılabilirlik boyutuna yönelik .81, etkililik boyutuna yönelik .88 ve memnuniyet boyutuna yönelik .84 olarak tespit edilmiştir. Araştırmacılara göre güvenirlik katsayısı 1'e yaklaştı̆̆ında güvenirlik 
artmaktadır. (Huang, Ryan, Zaber ve Palmer, 2014; Sekaran, 2003). Bu bağlamda ölçeğin ilgili boyutlarının her birinin güvenirlik katsayılarının "mükemmel" olduğu yorumu yapılabilmektedir.

\section{Doğrulayıcı Faktör Analizi}

Bu çalışmada Açımlayıcı faktör analizinde kullanılan aynı veriler üzerinden Doğrulayıcı faktör analizine gidilmiştir. Alan yazın incelendiğinde Schmitt (2011) yaptığı çalışmada aynı veriye önce AFA uygulayarak elde edilen yapıyı doğrulamak için DFA uygulamıştır. Önce açımlayıcı faktör analizi uygulanıp, açımlayıc faktör analizi ile keşfedilen modelin DFA ile test edilmesi ve kuramsal sağlamlığı yakalanmıştır.

\section{Yeterlilik ve Motivasyon Faktörü DFA}

Kavramsal çerçevede değerlendirilen ölçeğin YM Faktörüne ait doğrulayıcı faktör analiz sonuçları Şekil 2' de görülmektedir. Şekil 1'de S14, S15, S16, S17, S18, S19, S37 gözlenen değişkenleri temsil eden soru kodlardır.

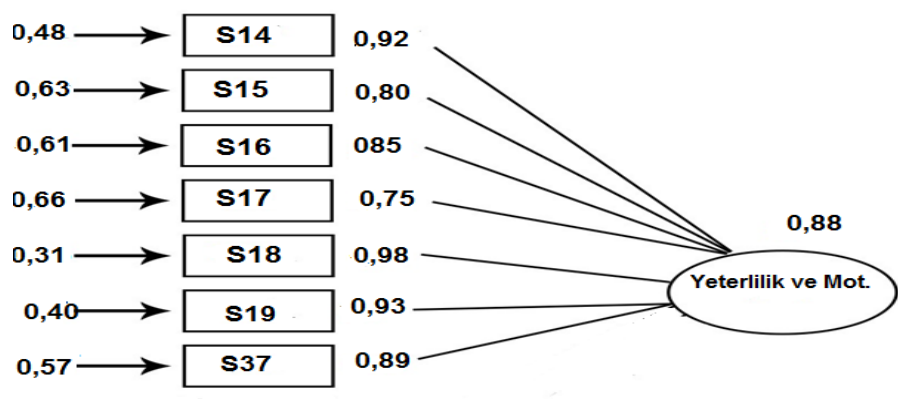

Şekil 2. Yeterlilik ve Motivasyon Faktörü için DFA

Şekil 2'deki DFA'da, Yeterlilik ve Motivasyon faktöründen gözlenen değişkenlere doğru yönlendirilmiş oklar üzerindeki değerler faktörün açıklanmasında yararlanılan her bir gözlenen değişkene ait standart regresyon katsayılarını (doğrulayıcı faktör analizi yükleri) göstermektedir. Ayrıca gözlenen değişkenlere ait hata değerleri ( $\mathrm{R}^{2}$ sonuçları) ise hata değerlerinden her bir gözlenen değişkene doğru yönlendirilmiş oklar üzerinde görülmektedir. Yukarıdaki şekle göre Yeterlilik ve Motivasyon faktörü en güçlü sorunun 19 nolu soru, en zayıf sorunun da 17 nolu soru oldu gözlenmektedir. 


\section{Yeterlilik ve Motivasyon Faktörü Uyum İndeksleri}

Tablo 2. Yeterlilik ve Motivasyon faktörü Uyum İndeksleri

\begin{tabular}{lllllll}
\hline & \multicolumn{2}{l}{ Uyum İndeksleri } & & & \\
\cline { 2 - 7 } Özellikler & $\chi^{2} / \mathrm{sd}$ & GFI & AGFI & TLI & CFI & RMSEA \\
\cline { 2 - 7 } & $269 / 14$ & .910 & .921 & .918 & .979 & .039 \\
\hline
\end{tabular}

Yeterlilik ve motivasyon faktöre ait nihai uyum indeksleri, Tablo 2'de görüldüğü gibi istenilen sinırlarda olduğu gözlenmiştir. GFI'nin .94, AGFI'nın .89, CFI'nin .93, modelin mükemmel uyum gösterdiğini kanitıdır (Anderson \& Gerbing, 1984; Cole, 1987). Buna göre Yeterlilik ve Motivasyon faktörüne ait nihai uyum indeksleri, Tablo 2' de görüldüğü gibi istenilen sınırlardadır.

\section{Kullanılabilirlik Faktörü DFA}

Kavramsal çerçevede değerlendirilen ölçeğin K Faktörüne ait doğrulayıcı faktör analiz sonuçları Şekil 3'de görülmektedir. Şekil 3'de ilgili maddeler gözlenen değişkenleri temsil eden soru kodlardır.
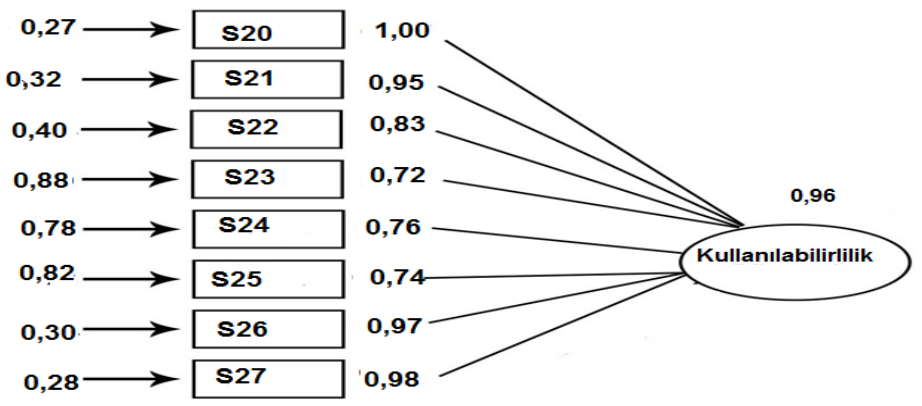

Şekil 3. Kullanılabilirlik Faktörü İçin DFA

Şekil 3'deki DFA'ya göre, Kullanılabilirlik faktöründe gözlenen değişkenlere doğru yönlendirilmiş oklar üzerindeki değerler faktörün açıklanmasında yararlanılan her bir gözlenen değişkene ait standart regresyon katsayılarını (doğrulayıc faktör analizi yükleri) göstermektedir. Yukarıdaki şekilde yer alan gözlenen değişkenlere ait hata değerleri ( $R^{2}$ sonuçları) ise hata değerlerinden her bir gözlenen değişkene doğru yönlendirilmiş oklar üzerinde görülmektedir. Kullanılabilirlik Faktöründe en güçlü sorunun 20 nolu soru, en zayıf sorunun da 23 nolu soru olduğu şekilde gözlenmektedir. 


\section{Kullanılabilirlik Faktörü Uyum İndeksleri}

Tablo 3. Kullanılabilirlik Faktörü Uyum İndeksleri

\begin{tabular}{lllllll}
\hline & \multicolumn{6}{l}{ Uyum İndeksleri } \\
\cline { 2 - 7 } Özellikler & $\chi^{2} /$ sd & GFI & AGFI & TLI & CFI & RMSEA \\
\cline { 2 - 7 } & $149 / 20$ & .900 & .870 & .910 & .929 & .014 \\
\hline
\end{tabular}

Kullanılabilirlik faktöre ait nihai uyum indeksleri, Tablo 3'de görüldüğü gibi istenilen sinırlarda olduğu gözlenmiştir. GFI ve AGFI değerlerinin 0.90 dan yüksek olması, RMSEA değerinin ise 0.08 den düşük çıkması, model veri uyumunu göstermektedir (Marsh ve Hocevar, 1988). Buna göre Kullanılabilirlik faktörüne ait nihai uyum indeksleri, Tablo3'de görüldüğü gibi istenilen sinurlardadır.

\section{Etkililik Faktörü DFA}

Kavramsal çerçevede değerlendirilen ölçeğin Etkililik Faktörüne ait doğrulayıcı faktör analiz sonuçları Şekil 4' de görülmektedir. Şekil ilgili maddeler gözlenen değişkenleri temsil eden soru kodlardır.

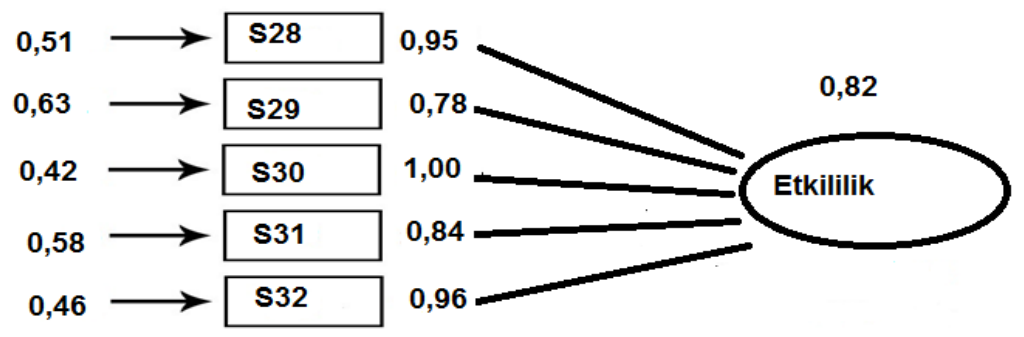

Şekil 4. Etkililik Faktörü İ̧in DFA

Şekil 4'deki DFA'ya göre; Etkililik faktöründe gözlenen değişkenlere doğru yönlendirilmiş oklar üzerindeki değerler faktörün açıklanmasında yararlanılan her bir gözlenen değişkene ait standart regresyon katsayılarını (doğrulayıcı faktör analizi yükleri) göstermektedir. Ayrıca şekilde yer alan gözlenen değişkenlere ait hata değerleri $\left(R^{2}\right.$ sonuçları) ise hata değerlerinden her bir gözlenen değişkene doğru yönlendirilmiş oklar üzerinde görülmektedir. Etkililik Faktöründe en güçlü sorunun 30 nolu soru, en zayıf sorunun da 29 nolu soru olduğu şekilde gözlenmektedir. 


\section{Etkililik Faktörü Uyum İndeksleri}

Tablo 4. Etkililik Faktörü Uyum İndeksleri

\begin{tabular}{|c|c|c|c|c|c|c|}
\hline \multirow[b]{3}{*}{ Özellikler } & \multicolumn{6}{|c|}{ Uyum İndeksleri } \\
\hline & $\chi^{2} / \mathrm{sd}$ & GFI & AGFI & TLI & CFI & RMSEA \\
\hline & $118 / 14$ & .879 & .907 & .927 & .968 & .088 \\
\hline
\end{tabular}

Etkililik faktöre ait nihai uyum indeksleri, Tablo 4' de görüldüğü gibi istenilen sinırlarda olduğu gözlenmişsir. Hooper, Caughlan ve Muller'e (2008) göre GFI, CFI, NFI, RFI, IFI ve AGFI indeksleri adına 0.90 kabul edilebilir uyum değeri, 0.95 ise mükemmel uyum değeri olarak kabul görmektedir. Bu bağlamda ilgili uyum indekslerinin mükemmel uyum değerlerini tespit ettiği saptanmıştır.

\section{Memnuniyet Faktörü DFA}

Kavramsal çerçevede değerlendirilen ölçeğin Memnuniyet Faktörüne ait doğrulayıcı faktör analiz sonuçları şekil 5'de görülmektedir. Şekil 5'de S33, S34, S35, S36, gözlenen değişkenleri temsil eden soru kodlardır.

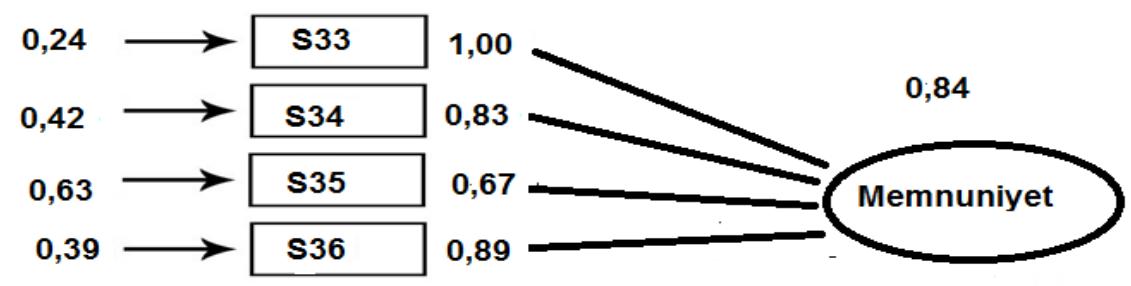

Şekil 5. Memnuniyet Faktörü İçin DFA

Şekil 5'deki DFA'ya göre, Memnuniyet faktöründen gözlenen değişkenlere doğru yönlendirilmiş oklar üzerindeki değerler faktörün açılanmasında yararlanılan her bir gözlenen değişkene ait standart regresyon katsayılarını (doğrulayıc faktör analizi yükleri) göstermektedir. Gözlenen değişkenlere ait hata değerleri ( $R^{2}$ sonuçları) ise hata değerlerinden her bir gözlenen değişkene doğru yönlendirilmiş oklar üzerinde görülmektedir. Şekil 5 incelendiğinde Memnuniyet Faktöründe en güçlü sorunun 33 nolu soru, en zayıf sorunun da 35 nolu soru olduğu görülmektedir. 


\section{Memnuniyet Faktörï Uyum İndeksleri}

Tablo 5. Memnuniyet Faktörü Uyum İndeksleri

\begin{tabular}{lllllll} 
& \multicolumn{2}{l}{ Uyum İndeksleri } & & & \\
\cline { 2 - 7 } Özellikler & $\chi^{2} / \mathrm{sd}$ & GFI & AGFI & TLI & CFI & RMSEA \\
\cline { 2 - 7 } & $112 / 11$ &, 868 &, 891 &, 876 &, 906 &, 041 \\
\hline
\end{tabular}

Memnuniyet faktöre ait nihai uyum indeksleri, Tablo 5’ de görüldüğ̈̈̈ gibi istenilen sinırlarda olduğu gözlenmiştir.

\section{Tartışma ve Sonuç}

Pandemi dönemi ile başlayan uzaktan eğitim süreci ile birlikte okullar ve üniversiteler bir dijitalleşme dönemi içerisine girmişlerdir. Bu dönemden en çok etkilenenler şüphesiz ki eğitim paydaşlarıdır (öğretmen, öğretim elamanları, öğrenciler, veliler). Bu noktada her bir paydaşın dijital teknolojileri kullanma konusunda hazırbulunuşlukları ön plana çıkmıştır. Teknolojiyi her alana entegre eden eğitim kurumları bu konuda başarılı olup sürece hemen uyum sağlarken, geri planda tutan kurumlar ise süreç yönetiminde zorlanmışlardır.

Ülkemizde genele baktığımızda, Yükseköğretim kademesinde sürecin başından itibaren uzaktan eğitim ortamlarının sunduğu imkanlardan; esneklik (zaman, coğrafi sınırlamalar), aynı anda daha fazla kişiye ve daha fazla veriye erişim, öğrenenlerin kendi hızında öğrenmesi, ders materyallerinin tekrar tekrar kullanımı gibi maksimum düzeyde yararlanılmaya çalışılmıştır. Pandemi sürecinde üniversitelerin kullandıkları uzaktan eğitim ortamları incelendiğinde; Moodle, Blackboard, Adobe Connect, Advancity, Canvas, Google ve Microsoft ürünleri sıralamada yerlerini almaktadır. Bu bağlamda Dikmen ve Bahçeci (2020) çalışmalarında, Pandemi sonrası yükseköğretim kurumlarında yaşanan eğitim öğretim faaliyetlerini, durum çalışması yöntemiyle araştırmışlardır. Sonuç olarak Türkiye'deki üniversitelerin çoğunluğunun uzaktan eğitim ve teknoloji altyapısının olduğu ortaya konulmuştur. Telli ve Altun (2020) çalışmalarında uzaktan eğitimin geçmiş yıllardaki gibi yüz yüze eğitime alternative olmak yerine eğitimin ana kaynağı olacağını savunmaktadır.

Özonur, Kamışlı, Yelken ve Tokmak (2019), yaptıkları araştırma sonucunda öğrencilerin, öğrenme yönetim sistemine ilişkin olumlu görüşler bildirdiğini bazı öğrencilerin ise özellikle öğrenci işleri hizmetlerinin aksaklıkları yönünde olumsuz görüş ortaya koyduğunu tespit etmişlerdir. 
Baimurzayev ve Tekedere (2019) bulut tabanlı moodle öğrenme yönetim sisteminin kullanılabilirliğini analiz ettiği çalışmada bulut tabanlı moodle' in web sitesinin iyi düzeyde kullanılabilir olduğu belirtilmektedir. Kocatürk Kapucu ve Uşun (2019) yapmış olduğu çalışmada 2018-2019 Eğitim-Öğretim yılı itibarıyla ülkemizde uzaktan eğitim uygulamalarına yer veren 90 devlet üniversitesinden yaklaşık yarısının öğrenme yönetim sistemi hizmetini açık kaynak kodlu veya özgün yazılımlar aracılığıyla kendi içerisinde sunarken diğer yarısının ise öğrenme yönetim sistemi hizmetini özel bir şirketten aldıklarını belirtmektedirler.

Özcan ve Emiroğlu (2020) yapmış oldukları durum çalışmasında kullanılmak üzere, bulut tabanlı ÖYS alternatiflerinden TalentLMS, Docebo, 360learning, LatitudeLearning, iSpring Learn ve Litmos üzerinde sistem ve servis özellikleri incelemesi yapılmıştır. Bu çalışma kapsamında ve verilen kriterlere göre karar vericilerin gerçekleştirdiği alternatifler arası ikili karşılaştırmalar sonucu TalentLMS en fazla önem derecesine sahip bulut tabanlı ÖYS olarak belirlenmiştir.

Bu araştırmada, pandemi sürecinde uzaktan eğitim ortamlarının kullanımına ilişkin öğrenen tutumları üzerinde durulmuş ve bu bağlamda geçerli ve güvenilir bir ölçek ortaya koyma amaçlanmıştır. Bu bağlamda bu araştırmayla ortaya konulan geçerliği ve güvenirliği kanıtlanmış ilgili ölçeğin, hem öğretmen/öğretim elamanı hem de farklı kademelerdeki öğrenci çalışma grupları üzerinde etkili bir şekilde kullanılacağı öngörülmektedir. Bunun yanı sıra ilgili ölçekle, paydaşların Covid-19 Pandemi süreci boyunca uzaktan eğitim araçlarını kullanım konusunda yaşadıkları sistemsel, donanımsal ve/veya psikolojik sorunlar ortaya konulacak ve bu bağlamda çözüm önerileri sunulmuştur. Araştırmanın çalışma grubunu 2019-2020 yılı Bahar Dönemi Sakarya Üniversitesi' nin çeşitli fakültelerinde ve Sakarya Uygulamalı Bilimler Üniversitesi Hendek MYO'nun farklı bölümlerde öğrenim gören toplam 321 öğrenci oluşturmaktadır.

"Pandemi Sürecinde Uzaktan Eğitim Ortamlarının Kullanımına İlişkin Tutum" ölçeğinin geçerlik çalışması olarak görünüş, kapsam ve yapı geçerliğine bakılmıştır. Ölçek maddelerinin çalışma grubu üzerindeki dağılımını göstermek için Açımlayıcı Faktör Analizi (AFA) yapılmıştır. AFA sonunda ölçeğin 24 madde ve dört boyutlu yapısı ortaya konulmuştur. Bu boyutlar; yeterlilik ve motivasyon (1), kullanılabilirlik (2), etkililik (3) ve memnuniyet (4)'dir. 
Ölçeğinin yeterliliğini test etmek için Kaiser-Meyer-Olkin (KMO) değerine bakılmış; bu bağlamda KMO değeri .93 olarak saptanmıştır. Ölçeğin alt boyutlarına yönelik yapılan istatistiksel analizler sonunda Cronbach Alpha ile hesaplanan iç tutarlık katsayıları yeterlik ve motivasyon boyutuna yönelik .94; kullanılabilirlik boyutuna yönelik .81, etkililik boyutuna yönelik .88 ve memnuniyet boyutuna yönelik .84 olarak tespit edilmiştir. Bu bağlamda ölçeğin ilgiliboyutlarının her birinin güvenirlik katsayılarının "mükemmel" olduğu kanitlanmıştır.

AFA uygulanan araştırmada elde edilen yapıyı doğrulamak için Doğrulayıcı Faktör Analizi uygulanmıştır. DFA sonucuna göre tüm boyutlara ait nihai uyum indekslerinin istenen sınırlarda olduğu kanıtlanmıştır. Özet olarak, yapılan tüm istatistiksel analizler ve elde edilen bulgular "Pandemi Sürecinde Uzaktan Eğitim Ortamlarının Kullanımına İlişkin Tutum” ölçeğinin geçerliliğini ve güvenirliğini doğrulamıştır. Bu bağlamda ilgili ölçek Covid 19 pandemi sürecinde uzaktan eğitim ortamlarının kullanımı ve bu ortamların bireyler üzerindeki psikometrik etkilerini saptamak bağlamında farklı kademeler ve araştırma boyutları tarafından kullanılması önerilen geçerliği ve güvenirliği kanıtlanmış bir ölçektir.

İleride yapılacak ilgili çalışmaları ve araştırmacılar adına sunulacak öneriler aşağıdadır:

- Bu çalışmanın çalışma grubu, 2019-2020 yılı Bahar Dönemi Sakarya Üniversitesi' nin çeşitli fakültelerinde ve Sakarya Uygulamalı Bilimler Üniversitesi Hendek MYO'nun farklı bölümlerde öğrenim gören toplam 321 öğrenci ile sınırlıdır. İleriki çalışmalar, daha farklı çalışma grupları ile gerçekleştirilebilir.

- İlgili ölçek, Yükseköğretim kademesinde öğrenim gören öğrenenler için geliştirilmiş ve uygulaması yapılmıştır. Geçerliği ve güvenirliği kanıtlanmış bu ölçek farklı öğrenim kademeleri için uyarlanabilir ve/veya uygulama sürecine gidilebilir. Bu bağlamda ölçeğin farklı çalışma gruplarına uygulanarak yapı geçerliğine ilişkin destekleyeceği kanıtlar sunulabilir.

Son olarak gelecek araştırmalara ve araştırmacılara yön vermek üzere ilgili ölçeğin kültürel ve coğrafik açıdan oluşturdukları farklılıklar yorumlanabilir. 


\title{
EXTENDED ABSTRACT
}

\section{Attitude Scale Regarding the Use of Distance Education Environments in the Pandemic Process}

\author{
Ezgi Pelin Yıldız - Metin Çengel - Ayşe Alkan \\ Kafkas University, Sakarya University, Ministry of National Education
}

Distance education is a synchronous (synchronous) education process where all participants also participate and communicate directly with each other, the online learning process managed by the teacher, or when the student enters the system in their own planned time frames. In this context, synchronous and asynchronous teaching environments are complementary to distance education. In this context, synchronous and asynchronous teaching environments are complementary to distance education. With the Covid-19 pandemic, which affects many countries in the world, our country was also affected, and face-to-face education was interrupted and the distant education system was introduced. Dikmen and Bahceci (2020) studies, the majority of universities in Turkey have revealed that the distance education and technology infrastructure. Thus, distance education applied at different levels has suddenly entered our lives, even though it is foreign to most stakeholders (teachers, students, lecturers, and managers). Individuals' demand for distance education has increased during the social isolation period that comes with pandemic.

In this study, the use of distance education environments and the psychometric effects of this use on individuals in the pandemic process are emphasized and in this context, it has aimed to establish a valid and reliable scale. The validity and reliability studies of the scale were conducted with 321 students studying in different departments of Sakarya University and Sakarya Applied Sciences University Hendek Vocational School.

A comprehensive literature review was conducted primarily for the development of the relevant scale. First of all, a 25 -item pool based on theoretical basis was created for the developed scale. In addition, 10 items were added to the item pool for demonstrating the demographic characteristics of the students. Expert opinion was received from 4 field experts, 1 assessment and 
evaluation specialist, 1 language specialist and 1 Psychological Counseling and Guidance specialist regarding the pool of items created. After the expert opinions, necessary arrangements were made and a trial form was created for pilot implementation. In pilot practice, a group of 15 people, equivalent to the actual practice, was studied. As a result of the pilot implementation, the items that were not understood by the students were changed and the original form of the scale was created after receiving the expert opinion again.

Exploratory Factor Analysis (EFA) was performed to show the distribution of the scale items on the sample. According to the results of exploratory factor analysis (EFA), the number of the scale items was reduced from 25 to 24 with the thought that the eigenvalue was disrupting its four-factor structure. The four-factor structure of the scale, consisting of 24 items with eigen value greater than 1 , explains $73.42 \%$ of the total variance. The fact that this explained variance rate is over $30 \%$ is considered sufficient in test development studies in behavioral sciences (Rennie 1997; Buyukozturk, 2018). The results obtained after the validity and reliability studies prove that the scale has a consistent structure in itself.

In order to test the reliability of the study, the internal consistency coefficient of the scale's 4 -factor structure, determined by Cronbach Alpha, was found to be .93 . The internal consistency coefficients calculated with Cronbach Alpha at the end of the statistical analysis for the sub-dimensions of the scale were .94 for the competence and motivation dimension; .81 for usability dimension, .88 for effectiveness dimension and .84 for satisfaction dimension. According to the researchers, when the reliability coefficient approaches 1, reliability increases (Huang, Ryan, Zaber and Palmer, 2014; Sekaran, 2003). When the literature is analyzed, Fraenkel and Wallen (2006) shows that the reliability coefficient lower than .60 indicates that the scale is quite weak, that it is between .60 and .70 is within acceptable limits and that it is above .80 is excellent. In this context, it can be interpreted that the reliability coefficients of each of the related dimensions of the scale are "perfect".

Confirmatory Factor Analysis was applied to confirm the structure obtained in the EFA-applied research. According to the CFA result, it was proved that the final fit indexes of all dimensions are within the desired limits. In summary, all the statistical analysis and findings obtained confirmed the validity and reliability of the scale of "The Use of Distance Education Envi- 
ronments in the Pandemic Process and its Psychometric Effects on Individuals" scale. In this context, the scale is a proven scale and validity recommended for the use of distance education environments in the Covid 19 pandemic process and to determine the psychometric effects of these environments at different levels and research dimensions.

\section{Kaynakça / References}

Anderson, J. C. ve Gerbing D.W. (1984). The effect of sampling error on convergence, improper solutions, and goodness-of-fit indices for maximum likelihood confirmatory factor analysis. Psychometrika, 49, 155-173.

Ayvaz Güven, C. ve Güven A.F. (2016). Moodle eğitim yönetim sistemi ile bilişim teknolojileri alanındaki örnek bir dersin uzaktan eğitim ile uygulaması. 5th International Vocational Schools Symposium, Kosova, Prizren, 8-20 Mayss 2016, vol.1, pp.10-21.

Baimurzayev, B. ve Tekedere, H. (2019). Bulut tabanlı moodle öğrenme yönetim sisteminin kullanulabilirlik analizi. TÜBAV Bilim Dergisi, 12(4), 16-25.

Bradford, P., Porciello, M., Balkon, N. ve Backus, D. (2007). The blackboard learning system: The be all and end all in educational instruction?. Journal of Educational Technology Systems 35(3), 301-314. DOI: 10.2190/X137-X73L-5261-5656

Büyüköztürk, Ş., Kilıç, Ç. E., Akgün, Ö. E., Karadeniz, Ş. ve Demirel, F. (2013). Bilimsel araştrma yöntemleri (2.Bastm). Pegem Akademi.

Cabı, E. (2016). Dijital teknolojiye yönelik tutum ölçeği. Kastamonu Eğitim Dergissi, 24 (3), 1229-1244.

Cole, D. A. (1987). Utility of confirmatory factor analysis in test validation research. Journal of Consulting and Clinical Psychology, 55, 1019-1031.

Dikmen, S. ve Bahçeci, F. (2020). Covid-19 pandemisi sürecinde küresel çapta uygulanan yükseköğretim kurumlarındaki uzaktan eğitim süreçleri hakkında durum çalısmast: Frrat Üniversitesi örneği. Turkish Journal of Educational Studies, 7(2), 7898. https://doi.org/10.33907/turkjes.721685

Erkorkmaz, Ü.,E., Demir, İ., Özdamar, O., Sanisoğlu, K., ve Yavuz, S. (2013). Doğrulayıc faktör analizi ve uyum indeksleri.

Esnaola-Arribillaga and M. J. Bezanilla, (2020). Levels of Moodle Use to Support University Face-to-Face Teaching. IEEE Revista Iberoamericana de Tecnologias del Aprendizaje, 15(3), 129-137. doi: 10.1109/RITA.2020.3008376.

Field, A. (2000). Discovering statistics using SPSS for Windows. Sage Publications Ltd. 
Hamilton, R., Vohs, K. D. ve McGill, A. L. (2014). We'll be honest, this won't be the best article you'll ever read: The use of dispreferred markers in word-of-mouth communication. Journal of Consumer Research, 41, 197-212. https://doi.org/10.1086/675926

Hooper, D. Coughlan, J. ve Mullen, M. R. (2008). Structural equation modelling: Guidelines for determining model fit. The Electronic Journal of Business Research Methods, 6(1), 53-60.

Huang, J. L., Ryan, A. M., Zabel, K. L. ve Palmer, A. (2014). Personality and adaptive performance at work: A metaanalytic investigation. Journal of Applied Psychology, 99(1), 162-179. DOI: 10.1037/a0034285

Kaleci, D. ve Kapıdere, M. (2014). Moodle için web tabanlı SCORM paketi tasarımu: Soru ve sinav hazırlama örneği. Öğretim Teknolojileri ve Öğretmen Eğitimi Dergisi, 3(2), 29-39.

Karakoç, F., Y. ve Dönmez, L. (2014). Ölçek geliştirme çalışmalarında temel ilkeler. Tpp Eğitimi Dünyası 13(40), 39-49. https://doi.org/10.25282/ted.228738

Kline, R. B. (2005). Methodology in the social sciences: Principles and practice of structural equation modeling (2nd ed.). Guilford Press. Abstract.

Mıdık, Ö. (2018). Tutumlarn ölçme ve değerlendirmesi. https://www.researchgate.net/publication/329989941 Tutumlarin olcme_ve d egerlendirmesi adresinden 26.11.2020 tarihinde erişilmiştir.

Moore, J.L., Dickson-Deane, C. ve Galyen, K. (2011). e-Learning, online learning, and distance learning environments: Are they the same? Internet and Higher Education, 14(2), 129-135.

Özcan, H. ve Emiroğlu, B. G. (2020). Bulut tabanh öğrenme yönetim sistemi seçiminde bulanık çok kriterli karar analizi yaklaşım. Bilişim Teknolojileri Dergisi, 13(1), 97111. https://doi.org/10.17671/gazibtd.589757

Özonur, M., Kamışlı, H., Yelken, T. Y. ve Tokmak, H. S. (2019). Uzaktan eğitim öğrencilerinin enocta öğrenme yönetim sistemi hakkmda görüşlerinin incelenmesi. Mehmet Akif Ersoy Üniversitesi Eğitim Fakültesi Dergisi, 50, $283-302$. https://doi.org/10.21764/maeuefd.407470

Rennie K., M. (1997). Exploratory and confirmatory rotation strategies in exploratory factor analysis. Bildiri Güneybatı Eğitim Araştırmalan Birlĭgi, Austin, Texas. San Antonio, Texas.

Rodrigues, S. (2020). Higher education teachers' needs concerning with the moodle and the impact of training received in the use of the platform : Case study in higher education. 15th Iberian Conference on Information Systems and Technologies (CISTI), Sevilla, Spain, 2020, 1-6, doi: 10.23919/CISTI49556.2020.9141162. 
Sekaran, U. (2003). Research methods for business a skill-building approach. 4th Edition, John Wiley \& Sons: New York. - References - Scientific Research Publishing.

Statistics Solution (2020). Expertise and dissertation process. https://www.statisticssolutions.com/ adresinden 15.08 .2020 tarihinde erişilmiştir.

Weil, M. M., Rosen, L. D., ve Wugalter, S. E. (1990). The etiology of computerphobia. Computers in Human Behavior, 6, 361-379.

Telli, G. ve Altun, D. (2020). Coronavirüs ve çevrimiçi (online) eğitimin önlenemeyen yükselişi. Üniversite Araştrrmalan Dergisi, 3(1), 25-34. https://doi.org/10.32329/uad.711110

Tuluk, A. ve Seferoğlu, S. S. (2016). Açık kaynak kodlu öğrenme yönetim sistemleri: Karşılaştırmalı bir inceleme. 2. Uluslararası Eğitim Teknolojisinde Yeni Eğilimler Konferansi [2nd International Conference on New Trends in Educational Technology] (INTET'2016). 03-04 Mayıs 2016, Gazimağusa, KKTC.

Yildız, E., P., Tezer, M. ve Uzunboylu, H. (2018). Student opinion scale related to moodle $\operatorname{lms}$ in an online learning environment: Validity and reliability study. International Journal of Interactive Mobile Technologies (iJIM), 12(4), 97. DOI: $\underline{10.3991 / \text { iijm.v12i4.9205 }}$

Younus, A., I. (2019). Use of learning management systems in education: Comparison of open source learning management systems. Eğitimde öğrenme yönetim sistemleri kullantm: Açık kaynak öğrenme yönetim sistemlerinin karşlaştırması. Yayımlanmamış Yüksek Lisans Tezi. Çankaya Üniversitesi Fen Bilimleri Enstitüsü Bilgisayar Mühendisliği Anabilim Dalı Bilgi Teknolojileri Bilim Dalı.

\section{Kaynakça Bilgisi / Citation Information}

Yıldız, E. P., Çengel, M. ve Alkan, A. (2021). Pandemi sürecinde uzaktan eğitim ortamlarının kullanımına ilişkin tutum ölçeği. OPUS-Uluslararası Toplum Araştırmaları Dergisi, 17(33), 132-153. DOI: 10.26466/opus. 811510 


\section{Ekler}

\section{Ek 1. Pandemi Sürecinde Uzaktan Ĕgitim Ortamlarinin Kullanimi Ve Bireyler Üze- rindeki Psikometrik Özellikleri Ölçeği Maddeleri}

\begin{tabular}{|c|c|c|c|c|c|c|}
\hline & & 5 & 4 & 3 & 2 & 1 \\
\hline & & 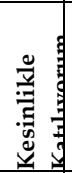 & 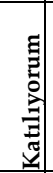 & 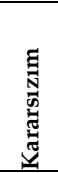 & 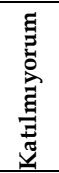 & 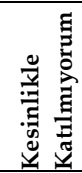 \\
\hline 1 & Bu platformu kullanmaktan keyif almaktayım. & & & & & \\
\hline 2 & $\begin{array}{l}\text { Pandemi sürecinden sonra da verilecek dersleri online (çevrimiçi) olarak bu } \\
\text { platform üzerinden almak isterim. }\end{array}$ & & & & & \\
\hline 3 & $\begin{array}{l}\text { Bu platform üzerinden eğitim süreçlerini zamandan ve mekandan bağımsız } \\
\text { olarak gerçekleştirmek kendi öğrenme hızımda çalışabilmeye teşvik etmektedir. }\end{array}$ & & & & & \\
\hline 4 & Bu platformu kullanmak kendime olan güvenimi arttırdı. & & & & & \\
\hline 5 & $\begin{array}{l}\text { Bu platformu kullanarak sınıf ortamında sormaktan çekindiğim soruları } \\
\text { sorma imkanı bulabilmem derse karşı olan cesaretimi arttırdı. }\end{array}$ & & & & & \\
\hline 6 & Bu platformda düzenlenen öğrenme etkinlikleriyle başarıya motive oldum. & & & & & \\
\hline 7 & Bu platformun kullanımının kolay olduğunu düşünüyorum. & & & & & \\
\hline 8 & Bu platforma giriş yapmadan önce birçok şey öğrenmem gerekti. & & & & & \\
\hline 9 & $\mathrm{Bu}$ platformu gereksiz bir şekilde karmaşık buldum. & & & & & \\
\hline 10 & $\begin{array}{l}\text { Pandemi sürecinden sonra da platformu sıklıkla kullanacağımı } \\
\text { düşünüyorum. }\end{array}$ & & & & & \\
\hline 11 & Platformun kullanımı konusunda kendimi donanımlı hissediyorum. & & & & & \\
\hline 12 & $\begin{array}{l}\text { Bu platformu kullanabilmek için teknik bir kişinin desteğine ihtiyacım } \\
\text { olabileceğini düşünüyorum. }\end{array}$ & & & & & \\
\hline 13 & $\begin{array}{l}\text { Platformun modüllerinin (ödev, forum, tartışma, kaynak, canlı ders vb.) } \\
\text { yararlı olduğunu düşünüyorum. }\end{array}$ & & & & & \\
\hline 14 & $\begin{array}{l}\text { Platform üzerinden aradığım hizmetlere (ekran paylaşımı, dosya hizmetleri, } \\
\text { kayıt, dosya paylaşımı ses-görüntü sistemleri vb.) kolaylıkla erişebilirim. }\end{array}$ & & & & & \\
\hline 15 & $\begin{array}{l}\text { Platformun sunduğu online (çevrimiçi) çalışmalardan öğrenme-öğretme sü- } \\
\text { reci boyunca etkili bir şekilde yararlanabilirim. }\end{array}$ & & & & & \\
\hline 16 & $\begin{array}{l}\text { Platformun sunduğu offline (çevrimdışı) çalışmalardan öğrenme-öğretme sü- } \\
\text { reci boyunca etkili bir şekilde yararlanabilirim. }\end{array}$ & & & & & \\
\hline 17 & $\begin{array}{l}\text { Platformun sağladığı uzaktan öğretimin, yüz yüze gerçekleştirilen geleneksel } \\
\text { öğretime göre öğrenme süreci üzerinde daha etkili olduğunu düşünüyorum. }\end{array}$ & & & & & \\
\hline 18 & $\begin{array}{l}\text { Bu platform ile sanal sınıf ortamlarındaki ders içeriklerine etkin bir şekilde } \\
\text { erişebilirim. }\end{array}$ & & & & & \\
\hline 19 & $\begin{array}{l}\text { Bu platform ile sanal sınıf ortamlarında dersi yürüten öğretim elemanları ile } \\
\text { etkin bir şekilde iletişim kurabilirim. }\end{array}$ & & & & & \\
\hline 20 & Bu platformda öğretim elemanları ile iletişim kurabilmekten memnunum. & & & & & \\
\hline 21 & Bu platformda ögrretim elemanlarından geri bildirim almaktan memnunum. & & & & & \\
\hline 22 & $\begin{array}{l}\text { Bu platformda ders içeriklerinin öğretim elemanları tarafından video ile an- } \\
\text { latılmasından memnunum. }\end{array}$ & & & & & \\
\hline 23 & $\begin{array}{l}\text { Platform üzerinden yürütülen online (çevrimiçi) derslerin tasarımından } \\
\text { memnunum. }\end{array}$ & & & & & \\
\hline 24 & $\begin{array}{l}\text { Platform ilgili çözemediğim bir sorun olduğunda teknik destek ve/veya } \\
\text { yardım alabilmekten memnunum. }\end{array}$ & & & & & \\
\hline 25 & Platform ortamında arkadaşlarımla iletişim kurabilmekten memnunum. & & & & & \\
\hline
\end{tabular}

